\title{
Portable Flow-Injection Analyzer for Nitrite and Nitrate in Natural Water
}

\author{
Shizuko HiRata, ${ }^{* \dagger}$ Sathrugnan KaRTHIKEYAN, ${ }^{*}$ and Tasuku KaJIYA**** \\ * Marine Resources and Environment, National Institute of Advanced Industrial Science and Technology \\ (AIST), 2-2-2 Hiro-suehiro, Kure 737-0197, Japan \\ **Graduate School, Kinki University, 1 Takaya-Uminobe, Higashi-Hiroshima 739-2116, Japan
}

\begin{abstract}
A portable flow-injection analyzer with solid-state spectrophotometric detection for the determination of nitrite and nitrate is described. It utilizes the Griess-Saltzman reaction. The instrument comprises a two-channel peristaltic pump, two six-port injection valves and a mini cadmium column between them. The sample loops were connected serially. The detection limits of the method were less than $7 \mu \mathrm{g} \mathrm{l}^{-1}$ for $\mathrm{NO}_{2}{ }^{-}$and $10 \mu \mathrm{g} \mathrm{l}^{-1}$ for $\mathrm{NO}_{3}{ }^{-}$.
\end{abstract}

(Received November 21, 2003; Accepted January 9, 2004)

Nitrogen dynamics play a key role in determining the ecological status and health of lowland rivers and estuaries. Eutrophication is of major concern in these ecosystems, and is strongly influenced by such factors as agricultural practices and industrial activities. ${ }^{1,2}$ Nitrate is the predominant dissolved species in most estuarine water and is derived from rock weathering, atmospheric deposition, diffused run-off from agricultural land and point-source discharges.

For nutrient biogeochemical cycling studies, conventional analytical procedures are based on manual sampling and the storage of samples prior to laboratory analysis. The integrity of the sample may not be preserved during storage, e.g., due to biological activity or chemical changes if correct sample handling protocols are not strictly followed. ${ }^{3}$ Therefore, a field deployable instrument is recommended for obtaining accurate and reliable data. There is continuous interest in developing miniaturized absorption or fluorescence detection devices for online measurement techniques using light emitting diodes (LEDs), which are inexpensive, and have a long life, high brightness, and low noise in conjunction with photo-diodes (PDs). Field-deployable instruments for nitrate ${ }^{3-5}$ and phosphate $^{6-8}$ in river-water samples have been reported. Recently, Gardolinski et al. described a miniature flow-injection analyzer for nitrate, which has been demonstrated in the laboratory, on shipboard and for in-situ monitoring. ${ }^{9}$ They have employed a longer path-length $(20 \mathrm{~mm})$ flow through a solid state detector in the instrument.

In the present work, the laboratory optimization of a field deployable, portable flow injection analyzer is presented for monitoring nitrite and nitrate in natural water. This instrument is light weight, cost effective and sensitive enough to monitor nitrite and nitrate in various locations of water. This instrument is shown to be operated reliably in the laboratory, and will be further tested for field measurements in the future.

\section{Experimental}

Reagents and chemicals

All chemicals used were of analytical reagent grades and

$\dagger$ To whom correspondence should be addressed.

E-mail: s-hirata@aist.go.jp deionized doubly distilled water was used throughout for solution preparation. A stock standard solution of nitrite, 1000 $\mathrm{mg} \mathrm{dm}-3$ was prepared by dissolving $0.1500 \mathrm{~g}$ of sodium nitrite in $100 \mathrm{ml}$ of water and nitrate; $1000 \mathrm{mg} \mathrm{dm}^{-3}$ was prepared by dissolving $0.1371 \mathrm{~g}$ sodium nitrate in $100 \mathrm{ml}$ of water. Working standard solutions were daily prepared by serial dilution of the stock solution. The carrier used was prepared by dissolving 1.5 $\mathrm{g}$ of ammonium chloride and $0.35 \mathrm{~g}$ of EDTA in $500 \mathrm{ml}$ of distilled deionized water. ${ }^{10}$ The optimized reagent solution consists of $1.0 \mathrm{~g}$ of sulfanilamide, $0.06 \mathrm{~g}$ of $N$-(1-naphthyl) ethylenediamine dihydrochloride (NEDA) and $2 \mathrm{ml}$ of conc. hydrochloric acid (Wako) in $200 \mathrm{ml}$ of water. ${ }^{11}$ The copperized cadmium for the column was prepared by mixing $1 \mathrm{~g}$ of $2-40$ mesh cadmium with $25 \mathrm{ml}$ of $2 \%$ (w/v) copper sulfate solution for 2 min, draining off the supernatant and rinsing with Milli-Q water. This was followed by mixing with $25 \mathrm{ml}$ of $2 \mathrm{M}$ hydrochloric acid for $2 \mathrm{~min}$, draining off the supernatant and rinsing with Milli-Q water, then washing with $1 \%(\mathrm{w} / \mathrm{v})$ ammonium chloride solution. It was then wet packed in a mini column $(25 \times 2 \mathrm{~mm}$ i.d. $)$ and stored in ammonium chloride.

\section{Instrumentation}

Figure 1 shows a schematic representation of the instrument which has been built in our laboratory. The instrument consists of a battery powered-12 V peristaltic pump Model MRP-P2 (Minato Concept, Japan) and two six-port injection valves (Upchurch Scientific, WA, USA), a $2.5 \mathrm{~cm}$ length $\times 2 \mathrm{~mm}$ i.d. copperized cadmium reduction column, an acrylic T-piece for mixing reagents, a $60 \mathrm{~cm}$ reaction coil and a flow-through, home-made solid-state detector. All of these components were fitted in a box (W $400 \times$ D $300 \times$ H $60 / 310 \mathrm{~mm})$. Teflon tubings were used to stream the carrier and the reagent. Flow rates of $0.3 \mathrm{ml} \mathrm{min}{ }^{-1}$ were used for the carrier and reagent streams. All of the connections were made using $0.5 \mathrm{~mm}$ i.d. PTFE tubings. The analog output of the transmittance was collected using a 32-bit-Daswizard PC card installed into a Celeron laptop computer, in which the raw data of transmittance were converted into absorbance using Excel ${ }^{\circledR}$ software.

The FI chemistry is based on diazotization and subsequent coupling with sulfanilamide and NEDA to produce a pinkpurple azo dye. This was quantified using a home-made flowthrough solid-state detector incorporating a green LED $\left(\lambda_{\max }=\right.$ $525 \mathrm{~nm}$ ) and a photo-diode OPT 301 (Texas Instruments, USA). 


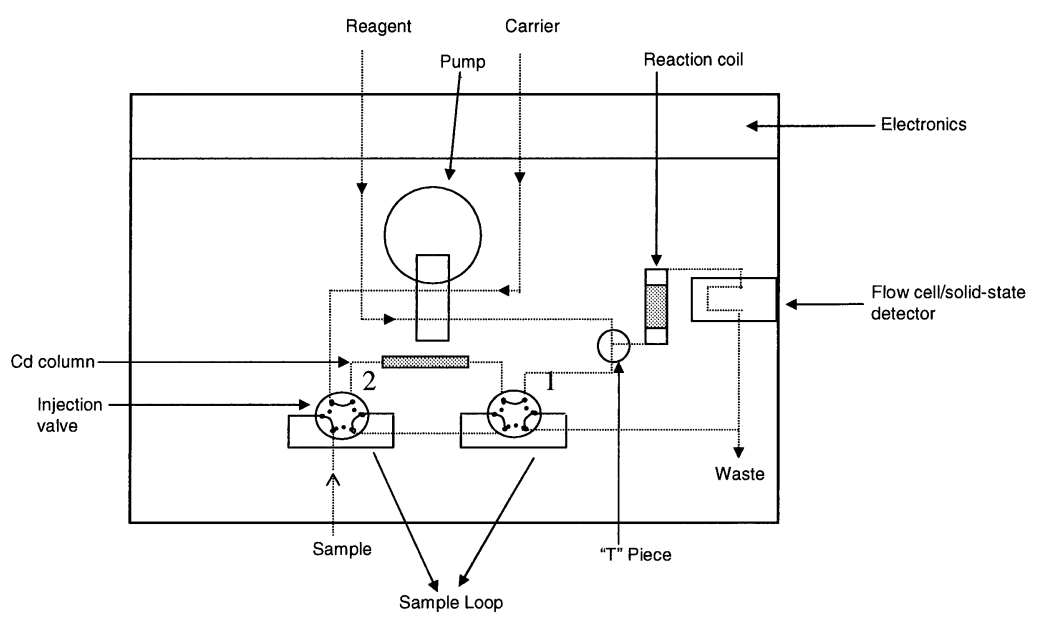

Fig. 1 Schematic layout of the portable nitrite-nitrate analyzer.

The flow cell was made from thick black rubber block. A detailed description of the flow-through absorbance detector was reported in our previous research. ${ }^{11}$ In the case of nitrate, it was reduced on-line to nitrite using a copperized cadmium column prior to a colorimetric reaction of nitrite. Two six-port injection valves were connected in parallel and a cadmium column was inserted in between, as shown in Fig. 1. This has resulted in a sequential determination of nitrite and nitrite plus nitrate. The nitrate was calculated from the difference.

\section{Operating procedures}

The sample loops were connected serially. The sample solution was manually injected simultaneously in two $250 \mu \mathrm{l}$ sample loops with a syringe. Firstly, the sample solution was loaded from the 1st valve (right side) into the carrier stream manually, mixed with the reagent stream with the help of the carrier and then nitrite was determined spectrophotometrically using a home-made $20 \mathrm{~mm}$ flow cell detector comprising of a green LED and a PD. The sample solution from the 2 nd valve (left side) was then manually loaded into the carrier stream 2 min later after the 1st valve sample loading. The sample solution from the 2 nd valve was passed through the copperized cadimium column, mixed with the reagent stream, and thereby nitrite + nitrate ions in the sample were determined sequentially. The first peak is due to nitrite ion and second one is due to both nitrite and nitrate ions. The concentration of nitrate was obtained from the difference.

\section{Water samples}

Seawater, river-water and estuarine-water, well-water and tapwater samples were collected from the Hiroshima region. All water samples were filtered through a $0.45 \mu \mathrm{m}$ Millipore filter and refrigerated. These samples were analyzed for nitrite and nitrate, as described above. The analysis was carried out within $24 \mathrm{~h}$. The concentration of nitrite and nitrate in unknown samples was calculated using a standard calibration graph.

\section{Results and Discussion}

\section{Laboratory optimization}

The entire instrument, including the FI manifold, electronics and the internal battery pack, was housed in one box (W $400 \times$ D $300 \times$ H 60/310 mm). The electronics were mainly fitted inside of the lid (H $60 \mathrm{~mm})$. This is truly portable because of the compact arrangement and its light weight. Two numbers of six-port injection valves were utilized to measure the nitrite and nitrate simultaneously. As per the FI manifold shown in Fig. 1, the nitrite present in the sample would be measured by the sample from the 1st valve (right side), while the nitrite plus nitrate would be measured by the sample from the 2 nd valve (left side). The determination of nitrate was achieved by on-line reduction to nitrite with the copperized cadmium column before its reaction with sulfanilamide and NEDA. From previous literature, ${ }^{9,10}$ it is prominent that the reduction should be carried out in a neutral or slightly alkaline medium to prevent any further reduction of $\mathrm{NO}_{2}^{-}$to $\mathrm{NO}^{-}$because of its similar electromotive forces $\left(E_{\mathrm{o}}\right)$. For this reason, ammonium chloride is usually employed as the carrier stream. Ammonium chloride in the carrier stream acts as both a complexant and a buffer. In our experimental studies, an ammonium chloride solution of $0.3 \%$ (w/v) at $\mathrm{pH} 8.0$ was found to be optimum for obtaining more than $95 \%$ reduction efficiency. A small concentration of EDTA $\{0.07 \%(w / v)\}$ was added into the ammonium chloride buffer stream to keep the $\mathrm{Cd} / \mathrm{Cu}$ surface active at all the time. ${ }^{10}$

For on-line reduction, the mini column's length in the range of $5-20 \mathrm{~cm}$ long has been employed by previous authors. ${ }^{9} \mathrm{We}$ have used a column of $2.5 \mathrm{~cm}$ length $(2 \mathrm{~mm}$ i.d.) which was sufficient for quantitative reduction (>95\%), which resulted in minimizing back pressure problems. The reduction efficiency of the proposed column was not deteriorated up to 200 injections. A reagent mixture containing $0.5 \% \quad(\mathrm{w} / \mathrm{v})$ sulfanilamide and $0.03 \%$ (w/v) NEDA, was employed for the azo dye colorimetric reaction. These concentrations were chosen from our previous optimization studies, ${ }^{11}$ and found to be suitable for the present experiments. The instrument description and optimized analytical parameters are given in Table 1.

\section{Analytical performance of the FI nitrite-nitrate analyzer}

After optimization studies, calibration experiments in the range of $25-200 \mu \mathrm{g} \mathrm{l}^{-1}$ were carried out for $\mathrm{NO}_{2}, \mathrm{NO}_{3}$ and $\mathrm{NO}_{2}$ $+\mathrm{NO}_{3}$ separately. As expected, the nitrite signals from the 2nd valve were less compared to the same of the 1 st valve. This was due to a dispersion effect. The linear regression equation for $\mathrm{NO}_{2}$ from the 1st valve and 2nd valve were $y=0.52 x\left(r^{2}=\right.$ $0.998)$ and $y=0.312 x\left(r^{2}=0.929\right)$, respectively. The linear regression equation for $\mathrm{NO}_{2}{ }^{-}+\mathrm{NO}_{3}{ }^{-}$from the 1 st valve was 


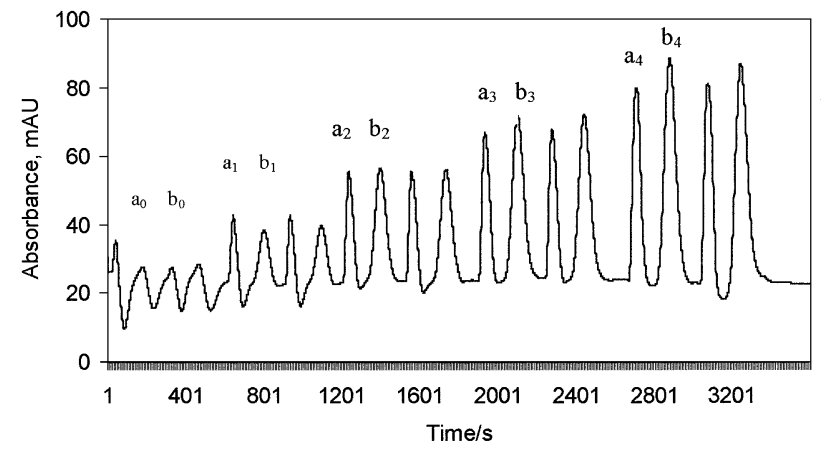

Fig. 2 Flow signals of nitrite and nitrate using the proposed portable flow-injection analyzer. $\mathrm{a}_{0}, \mathrm{a}_{1}, \mathrm{a}_{2}, \mathrm{a}_{3}$, and $\mathrm{a}_{4}: 0,25,50,75$, and $100 \mu \mathrm{g} \mathrm{l}^{-1} \mathrm{NO}_{2}^{-} ; \mathrm{b}_{0}, \mathrm{~b}_{1}, \mathrm{~b}_{2}, \mathrm{~b}_{3}$, and $\mathrm{b}_{4}: 0,25,50,75$, and $100 \mu \mathrm{g} \mathrm{l}^{-1}$ $\mathrm{NO}_{2}^{-}+\mathrm{NO}_{3}^{-}$.

$y=0.52 x\left(r^{2}=0.998\right)$. Further, the linearity was tested for a higher concentration in the range of $0.025-5 \mathrm{mg} \mathrm{l}^{-1}$ for $\mathrm{NO}_{2}$ and $\mathrm{NO}_{3}$, individually, for which the $R^{2}$ was better than 0.990 . This indicates the feasibility of the instrument for working in dynamic concentration range. Figure 2 depicts flow signals for $\mathrm{NO}_{2}$ and $\mathrm{NO}_{3}$ in the concentration range of $25-100 \mu \mathrm{g} \mathrm{l}^{-1}$. The detection limits for $\mathrm{NO}_{2}$ and $\mathrm{NO}_{3}$ were calculated based on a three-times standard deviation of a blank signal with 10 replicates. The repeatability of the method was tested by analyzing $\mathrm{NO}_{2}$ and $\mathrm{NO}_{3}$ standards at 50 and $100 \mu \mathrm{g} \mathrm{l}^{-1}$ levels for 10 times, and the calculated RSD was less than 5.4\%. The analytical merits are summarized in Table 2.

\section{Analysis of water samples}

The applicability of the portable nitrite-nitrate analyzer was tested by several types of water samples, such as tap, well, river, estuary and seawater samples. These water samples were collected in the Hiroshima region and analyzed for nitrite and nitrate using the proposed instrument, as described in "Experimental". The results are given in Table 3. The nitrite concentrations were very low in the range of $7-124 \mu \mathrm{g} \mathrm{l}^{-1}$, while the nitrate concentrations were high in the range of 0.37 $8.24 \mathrm{mg} \mathrm{l}^{-1}$. The nitrate plus nitrate signal for well, tap and river-water samples were accounted for nitrate only, since nitrite concentrations were insignificant. Further, the method was validated by spiking experiments in the range of $25-50 \mu \mathrm{g}$ $1^{-1}$ for $\mathrm{NO}_{2}$ and $0.5-1.0 \mathrm{mg}^{-1}$ for $\mathrm{NO}_{3}$. The recoveries were in the range of $93-102 \%$.

We have presented a cost-effective portable flow-injection analyzer for nitrite-nitrate analysis in various water samples. The applicability was presently demonstrated by laboratory measurements. It will be tested for field measurements in the future. Their results will be discussed separately.

\section{Acknowledgements}

We thank the associate Prof. Kei Toda, Kumamoto University, Kumamoto, Japan, for his useful guidelines and support for constructing this portable nitrite-nitrate analyzer.

\section{References}

1. S. R. Aston, in "Chemistry and Biogeochemistry of Estuaries", ed. E. Olasson and I. Cato, 1980, Wiley, Chichester, 452.

2. H. M. Bosch, A. B. Rosenfield, R. Huston, H. R. Shipman,
Table 1 Description of the portable nitrite-nitrate analyzer

\begin{tabular}{ll}
\hline Housing material & Wooden box \\
Analyzer size & W $400 \mathrm{~mm} \times \mathrm{D} 300 \mathrm{~mm} \times \mathrm{H} 60 / 310 \mathrm{~mm}$ \\
Analyzer weight & $\sim 10 \mathrm{~kg}($ including reagent and carrier bottles $)$ \\
Carrier & $0.3 \%($ w/v $) \mathrm{NH}_{4} \mathrm{Cl}+0.05 \%(\mathrm{w} / \mathrm{v})$ EDTA \\
Reagent & $0.5 \%(\mathrm{w} / \mathrm{v})$ sulfanilamide $+0.03 \%(\mathrm{w} / \mathrm{v}) \mathrm{NEDA}$ \\
Cd/Cu column & $25 \times 2 \mathrm{~mm}^{-} . \mathrm{d}$. \\
Flow rate & $0.3 \mathrm{ml} \mathrm{min}-1$ \\
Sample loop & $250 \mu \mathrm{l}$ \\
Reaction coil length & $60 \mathrm{~cm}$ \\
Optical path length & $20 \mathrm{~mm}$ \\
Detector & LED $\left(\lambda_{\max }=525 \mathrm{~nm}\right) / \mathrm{PD}(\mathrm{OPT} 301)$ \\
Data collection & DAS WIZARD PC CARD \\
\hline
\end{tabular}

Table 2 Analytical performance of the nitrite-nitrate analyzer

\begin{tabular}{lcc}
\hline \multicolumn{1}{c}{ Parameter } & Nitrite & Nitrate \\
\hline Working range $\left(\mathrm{mg} \mathrm{l}^{-1}\right)$ & $0.007-5.0$ & $0.01-5.0$ \\
Slop value & 0.52 & 0.2333 \\
Regression coefficient $\left(r^{2}\right)$ & 0.998 & 0.997 \\
DL $(3 \sigma) \mu \mathrm{g} \mathrm{l}^{-1}(n=7)$ & 7 & 10 \\
R.S.D $(\%)(n=7)$ & $4.5\left(50 \mu \mathrm{g} \mathrm{l}^{-1}\right)$ & $5.4\left(100 \mu \mathrm{g} \mathrm{l}^{-1}\right)$ \\
Sampling frequency $\left(\mathrm{h}^{-1}\right)$ & 15 & 15 \\
\hline
\end{tabular}

Table 3 Analysis of water samples

\begin{tabular}{|c|c|c|c|c|}
\hline \multirow[b]{2}{*}{ Sample } & \multicolumn{2}{|c|}{ Nitrite $\mathrm{NO}_{2}{ }^{-} / \mu \mathrm{g}^{-1}$} & \multicolumn{2}{|c|}{ Nitrate $\mathrm{NO}_{3}^{-} / \mathrm{mg}^{-1}$} \\
\hline & $\begin{array}{c}\text { Std } \\
\text { addition }\end{array}$ & $\begin{array}{c}\text { Obtained } \\
\text { value }\end{array}$ & $\begin{array}{c}\text { Std } \\
\text { addition }\end{array}$ & $\begin{array}{c}\text { Obtained } \\
\text { value }\end{array}$ \\
\hline \multirow{3}{*}{ Seawater } & - & $124 \pm 5$ & - & $0.37 \pm 0.03$ \\
\hline & 25 & $150 \pm 5$ & 0.5 & $0.86 \pm 0.03$ \\
\hline & 50 & $171 \pm 4$ & 1.0 & $1.35 \pm 0.02$ \\
\hline \multirow[t]{2}{*}{ Estuary water } & - & $33 \pm 2$ & - & $1.54 \pm 0.01$ \\
\hline & 50 & $85+2$ & 0.5 & $2.01+0.01$ \\
\hline \multirow[t]{2}{*}{ River water } & - & $15 \pm 3$ & - & $1.01 \pm 0.03$ \\
\hline & 50 & $62+2$ & 0.5 & $1.49+0.02$ \\
\hline \multirow[t]{2}{*}{ Well water } & - & $10 \pm 4$ & - & $8.24 \pm 0.30$ \\
\hline & 50 & $56 \pm 3$ & 1.0 & $9.23 \pm 0.29$ \\
\hline \multirow[t]{2}{*}{ Tap water } & - & $<7$ & - & $2.08 \pm 0.02$ \\
\hline & 50 & $55 \pm 3$ & 0.5 & $2.57 \pm 0.02$ \\
\hline
\end{tabular}

Average of triplicates.

and R. L. Woodward, J. Am. Water Works A, 1950, 42 , 161.

3. J. R. Clinch, P. J. Worsfold, and H. Casey, Anal. Chim. Acta, 1987, 200, 523.

4. H. Casey, R. T. Clarke, S. M. Smith, J. R. Clinch, and P. J. Worsfold, Anal. Chim. Acta, 1989, 227, 379.

5. N. J. Blundell, P. J. Worsfold, H. Casey, and S. Smith, Environ. Intern., 1995, 21, 205.

6. S. Karthikeyan, S. Hasigaya, T. Kajiya, and S. Hirata, Anal. Bioanal. Chem., 2004, in press.

7. G. Hanrahan, M. Gledhill, P. J. Fletcher, and P. J. Worsfold, Anal. Chim. Acta, 2001, 440, 55.

8. P. J. Worsfold, R. Clinch, and H. Casey, Anal. Chim. Acta, 1987, 197, 43.

9. P. C. F. C. Gardolinski, A. R. J. David, and P. J. Worsfold, Talanta, 2002, 58, 1015.

10. K. Higuchi and S. Motomizu, Anal. Sci., 1998, 15, 129.

11. S. Hirata, B. Vijayalekshmi Amma, S. Karthikeyan, and K. Toda, Anal. Sci., 2003, 19, 1687. 